\title{
Space Vector Modulation Technique Applied to Doubly Fed Induction Generator
}

\author{
V. Meenakshi*, G. D. Anbarasi , Jebaselvi and S. Paramasivam \\ Department of Electrical and Electronics Engineering, Faculty of Electrical and Electronics Engineering, \\ Sathyabama University, Jeppiaar Nagar, Rajiv Gandhi Salai, Chennai - 600119, Tamil Nadu, India; \\ meenagovind1@yahoo.in, anbarasi.jebaselvi@gmail.com, paramsathya@yahoo.com
}

\begin{abstract}
In this paper, implementation of SVPWM switching technique for a constant frequency, variable speed wind turbine is carried out. The modeling and simulation is done using MATLAB/Simulink for doubly-fed induction generator. The total harmonic distortion for various parameters like stator current, rotor speed and electro-magnetic torque of this wind electric generator has been obtained. The reduction in distortion level is higher compared to other pulse width modulation techniques.
\end{abstract}

Keywords: Control Strategy, DFIG, SVPWM, THD

\section{Introduction}

The limitations in integrating the wind energy with solar energy or diesel generators with the goal of attaining reliable and uninterruptible energy supply are ${ }^{1}$. The maintenance of DC link voltage constant in real time is not presumable ${ }^{2}$. Harmonic factors in calculating Total Harmonic Distortion (THD) is not considered ${ }^{3}$. New control strategies challenging the problems in controlling frequency, voltage and other electrical quantities are not considered ${ }^{4}$. Variable speed variable pitch DFIG based wind turbine system are not dealt in detail ${ }^{5}$. The magnitude of rotor and stator voltage vectors decide the asynchronous torque and the synchronous torque. The synchronous torque depends on torque angle $\delta$ between stator and rotor space vectors, while it is not considered for asynchronous torque ${ }^{6}$.

Comparison of control techniques like SVPWM and SPWM for inverter has been made but limited to specific machines ${ }^{7}$. THD is found to be high in all the related quantities $^{8,9}$. The mechanical complexity due to pitch control is studied but the effects of electrical components alone taken into consideration to model the wind, wind turbine and its controllers by suitable control techniques ${ }^{10}$.
Three level VSI using SVPWM techniques in which the switching frequency varies widely with variable speed drive frequency, a main drawback in three level scheme $^{11}$. Comparison of SVPWM and SPWM switching techniques is done using $\mathrm{PSCAD}^{12}$. The electromagnetic torque is higher than the rated value ${ }^{13}$. Fast Fourier Transform (FFT) analysis for THD has not been done in this paper ${ }^{14}$. SVPWM switching techniques is used for PMSG, but it has low efficiency compared to DFIG ${ }^{15}$. Voltage oriented control has been dealt in combination with direct power control for hybrid scheme constituting wind driven generators and PV modules ${ }^{16}$ this paper, the simulation of DFIG with SVPWM switching technique has been carried out. The THD in variable speed wind power generation system using DFIG is found using FFT analysis. The reliability of complete wind turbine system using DFIG has been analyzed by Markov Process ${ }^{17}$. Using Particle swarm optimization technique, three important control parameters such as pitch angle, rotor speed and stator voltage has been adjusted and the appropriate controllers are tuned ${ }^{18}$. Various parameters like wind speed, solar irradiation, marine velocity are taken and program in MATLAB platform to get improved voltage and real power ${ }^{19}$. A lookup table is done using different speed and

${ }^{*}$ Author for correspondence 
different loads using neural network for standalone load to obtain constant stator voltage ${ }^{20}$. In order to get optimum power improved controller in wind turbine is used based on human mind's emotional learning is consid$\operatorname{ered}^{21}$. Sliding mode control strategy is used in machine side converter and grid side converter because of that cost is reduced and complication is extensively reduced ${ }^{22,23}$

The FFT analysis has been done for the most important electrical and mechanical quantities such as rotor speed, stator current and electromagnetic torque which determines the performance characteristics of DFIG. The boost converters and inverters are utilized as ac-dc-ac converters for the variable speed wind power generation system. The variable frequency obtained from the DFIG is converted into the fixed frequency output irrespective of the variable wind speed and generator output. The level of harmonics in the inverter circuit is largely reduced with the implementation of space vector modulation. Thus the simulation is developed to demonstrate the effectiveness of the system. The stator flux and the rotor speed can be improved by selecting suitable control strategy using SVPWM in order to get the maximum output. The complete model is simulated under variable speed operation using MATLAB/Simulink/Sim Power Systems to study the overall performance characteristics of DFIG.

This paper is organized in such a way that the section 2 overviews the static and dynamic characteristic of DFIG. Various control strategies employed in DFIG are discussed in section 3. section 4 describes the SVPWM control technique and its simulation results. section 5 concludes with future implements and scopes.

\section{Performance Characteristic of DFIG}

DFIG is a multiphase wound rotor and a multiphase slip ring assembly with brushes for accessing the rotor windings. Stator winding is directly connected to the three-phase grid and the rotor winding is fed from the grid through a back to back voltage source converter. The term 'Doubly Fed' refers to the fact that the stator voltage is supplied from the grid and the rotor voltage is induced by the power converter. This system allows a variable-speed operation over a large range.

Doubly fed machines are typically used in applications that require varying speed of the machine's shaft in a limited range around the synchronous speed. The superior feature of DFIG compared to the ordinary induction generators is that the active power obtained is both from stator and rotor windings. i.e. the rotor winding in DFIG contributes additional energy exchange between DFIG and grid.

Also it is able to equally import from utility grid and export the reactive power by means of power electronic converter. This leads to power system stability and allows the machine to support the grid during several voltage disturbances such as low voltage ride through. Any dc electric generator can be connected to power network by adjusting its open-circuit terminal voltage to match the network voltage by either adjusting its speed or its field excitation; the exact engine speed is not critical. In order to control speed and excitation, both the amplitude and the timing of the network voltage should be matched with an ac generator. Controlling of rotor voltages and currents enables the induction machine to remain synchronized with the grid although the wind speed varies. A wind turbine with the varying speed utilizes the available wind resource more efficiently than a fixed speed wind turbine, especially during low wind speed conditions. DFIG control is performed by different control gains and network voltage control through stator side and rotor side converters in order to attain stability in wind turbine operation.

During any fault, the current can be limited by various algorithms, series and dynamic voltage restorer be necessary been proposed for fault ride through, FRT in active crowbar in rotor circuit. The key factor of DFIG used as a wind electric generator is that it can be operated at variable speed mode keeping the amplitude and frequency of the generated voltage constant. Optimization of power generated as a function of the wind speed and the virtual elimination of sudden variations in the rotor torque and generated output power can be done easily in order to get a unity power factor. The converter compensates the difference between the mechanical and electrical frequencies by injecting a rotor current with a variable frequency. Hence, the operation and behavior of the DFIG is governed by the power converter and its controllers.

\subsection{Static Characteristics}

In wind power system, the mechanical power to be delivered to the electrical system is determined as:

$$
P_{m}=0.5 \rho A C_{p}(\lambda, \beta) v_{w}^{3}
$$


Where $\mathrm{Cp}$ depends on the tip speed ratio $\lambda$, and pitch angle $\beta$ :

$$
\lambda=\omega_{r} R / \nu_{w}
$$

\subsection{Dynamic Characteristics}

DFIG can be operated as a hybrid of an asynchronous and synchronous machine. As a synchronous generator, its torque depends mainly upon the torque angle $\delta$ between the rotor voltage and the stator feed voltage vector and as an asynchronous machine it depends on the slip s. The generator fed both from the stator and the rotor sides produces electromagnetic torque as a function of rotational speed. The expression of electromagnetic torque in the stationary mode is given by:

$$
T=\frac{3}{2} p L_{m}\left(I_{r d} I_{s q}-I_{r q} I_{s d}\right)
$$

Lm - mutual inductance

Ird - rotor direct -axis current

Isq - stator quadrature -axis current

Irq- rotor quadrature -axis current

Isd- stator direct -axis current

To calculate the torque in the steady state mode, the stator and the rotor current vector components in asynchronous operation as well as the rotor voltage in reference frame dq axis in synchronous mode need to be considered.

The mathematical equation for the electromagnetic torque in the steady state can be obtained as:

$$
T_{g}=T_{s}+T_{r}+T_{s r \cos }+T_{s r \sin }
$$

Where $T_{s}$ - asynchronous torque component due to feed on stator and $T_{r}$ - Torque component due to feed on rotor:

$T_{\text {srcos }}+T_{\text {srin }}-$ Synchronous torques caused by the excitation of rotor voltage vector components. The addition of the asynchronous torques Ts and $T_{r}$ are approximately equal in magnitude with the synchronous torque, but have opposite signs. Consequently, the amount and the sign of the total generator torque are mainly determined by the synchronous torque component.

\subsection{Torque/Speed Curve of DFIG}

Asynchronous torque component depends on stator voltage and rotor voltage representing constant values but different in sign, while synchronous torque component substantially determines total generator torque. Hence the total DFIG electromagnetic torque is obtained by adding both the components.

The synchronous torque components Tsrsin, Tsrcos and the total DFIG torque Tg depends on the angle $\delta$, the asynchronous components $\mathrm{Tr}$ and Ts are independent of $\delta$. For angles $\delta=90^{\circ}$ and $270^{\circ}$, the synchronous component of the torque Tsrcos is zero and for angles $\delta=0^{\circ}$ and $180^{\circ}$ the synchronous component of the torque Tsrsin obtained is zero. The magnitude and sign of the total torque is determined by the synchronous component Tsroos for angles $\delta=90^{\circ}$ and $270^{\circ}$. The total electromagnetic torque $\mathrm{Tg}$ should be negative for angle $\delta=90^{\circ}$ and positive for angle $\delta=270^{\circ}$.

\section{Control Strategies in DFIG}

Generally ac drives require high power, variable voltage and variable frequency supply for their operation. Pulse width modulation techniques have been used to achieve variable voltage and variable frequency in ac-dc and dc-ac converters. This technique has been also used in applications such as static frequency changers SFC, uninterruptible power supplies UPS, DFIG etc. Some major PWM techniques in DC/AC inverters are Sinusoidal PWM (SPWM), Triangular wave sampling-Natural sampling, Uniform sampling, calculation based on equal area criterion, selective harmonics elimination, hysteresis control, Space Vector Modulation SVM or SVPWM, Random PWM and Current Controlled PWM (CCPWM) techniques. The main purpose of pulse width modulation technique in power inverters is to control the output voltage. Change in pulse-widths for middle and boundary pulses are obtained to improve inverter operation with less generation of harmonics. The most widely used PWM schemes for DFIG are carrier-based sinusoidal PWM and space vector PWM.

\subsection{Sinusoidal Pulse Width Modulation Technique}

SPWM is the mostly used method in motor control and inverter application. In SPWM technique, three sine waves Ur and a high frequency triangular carrier wave Uc are used to generate PWM signal in three phase inverter. The three phase sinusoidal signal is called reference signal and they are mutually $120^{\circ}$ phase shifted with each other. 


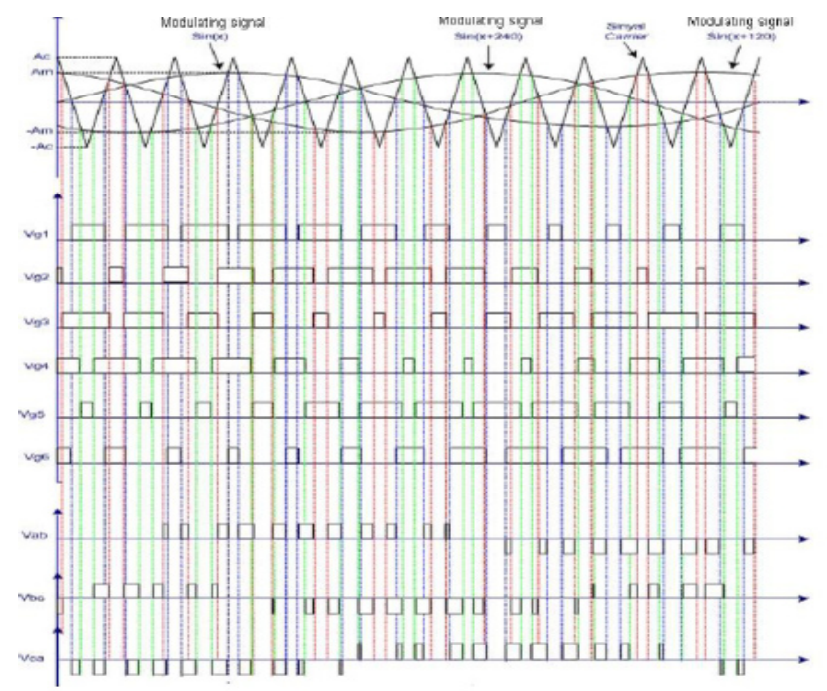

Figure 1. SPWM generation technique for three phasevoltage source inverter'.

The sinusoidal waves frequency is equal to the inverter output frequency $(50 / 60 \mathrm{~Hz})$. The high frequency carrier triangular wave is compared with the sinusoidal wave. The comparator generate the output pulse when $\mathrm{Ur}>\mathrm{Uc}$ and it triggers the respective inverter switch. In order to avoid undefined switching states and undefined AC output line voltages in the VSI, two switches in the same leg never should be switched on simultaneously. The ratio between the Uc and Ur must be an integer N.

Amplitude modulation ratio is given by:

$$
m_{a}=\frac{A_{r}}{A_{c}}
$$

Frequency modulation ratio is given by:

$$
m_{f}=\frac{F_{r}}{F_{c}}
$$

Total harmonic distortion is given as:

$$
T H D=\frac{\sqrt{V_{o u t}^{2}-V_{1}^{2}}}{V_{1}^{2}}
$$

Where, V1 = Fundamental components.

More number of control techniques are being adopted to improvise both the power regulation and control strategies among which the sliding mode power control, carrier-based sinusoidal PWM and SVPWM are worth to mention. In sliding mode control, no chatter in the generated torque produced that could lead to increased mechanical stress because of strong torque variations. Some draw backs of SPWM technique is that the total harmonic distortion is more, modulation index is less, current produced is less and hence the above draw backs are overcome by using SVPWM technique.

\section{Simulation of SVPWM Switching Techniques}

Space Vector Pulse Width Modulation is normally developed as vector approach to Pulse Width Modulation for three phase inverters. SVPWM has a unique feature that it tackles all the major issue related to the SPWM techniques such as computational complexity, synchronization, total harmonic distortion, dc bus voltage balancing and common mode voltage. Therefore, the proposed SVPWM method is suitable for high-power applications as it eliminates sub harmonics by maintaining synchronization, improves THD through various waveform symmetries. Avoiding harmonics can prevent the overheats and malfunction in sensitive systems. The space vector PWM has been increasingly used recently. In this modulation, three separate modulators for each of the three phases are not used but processed with the complex reference voltage vector as a whole.

The general topology of three phase voltage source inverter is shown in Figure 2. The IGBT switches in the same leg of VSI should not be turned on rather it will cause DC supply short circuited. So the switching operation is made complementary within the same leg. In SVPWM technique, eight switching states are included in the inverter, out of eight, two are zero switching states or zero vectors $\mathrm{V} 0$ and $\mathrm{V} 7$ and other six are non-zero switching state or active state V1 to V6. The switching vectors along with the corresponding line to line voltage are given in the Table 1.

To implement SVPWM switching technique, a revolving reference voltage Vector (Vref) is provided as voltage reference instead of three phase modulating waves. While plotting the eight voltage vectors in complex plane, the six active vectors (V1 to V6) form the axes of a hexagon as shown in Figure 3, supplies power to the load. The other two zero vectors ( $\mathrm{V} 0$ and $\mathrm{V} 7$ ) are located in the origin and supply no power. The reference vector is taken between the two adjacent active switching vectors and one or both of the zero vectors. This voltage vector (Vref) is used to modulate the inverter output. Vref is shown in the first sector of the two adjacent voltage vectors namely V1 and 


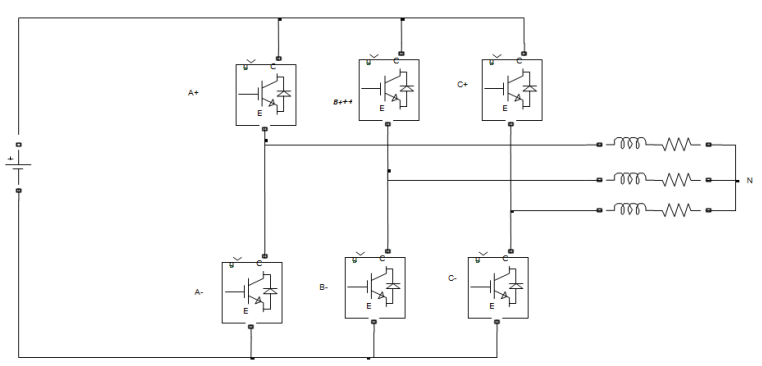

Figure 2. Three phase voltage source inverter.

Table 1. Switching states and line to line voltage

\begin{tabular}{|c|c|c|c|c|c|c|c|c|c|c|}
\hline \multirow[t]{2}{*}{$\begin{array}{l}\text { Voltage } \\
\text { vector }\end{array}$} & \multirow[t]{2}{*}{$\begin{array}{c}\text { Switching } \\
\text { vector }\end{array}$} & \multirow[t]{2}{*}{ A+ } & \multirow[t]{2}{*}{ B+ } & \multirow[t]{2}{*}{$\mathrm{C}+$} & \multirow[t]{2}{*}{ A- } & \multirow[t]{2}{*}{ B- } & \multirow[t]{2}{*}{ C- } & \multicolumn{3}{|c|}{$\begin{array}{l}\text { Line to Line } \\
\text { voltage }\end{array}$} \\
\hline & & & & & & & & Vab & $\mathrm{Vbc}$ & Vca \\
\hline V0 & 000 & OFF & OFF & OFF & ON & ON & ON & 0 & 0 & 0 \\
\hline V1 & 100 & ON & OFF & OFF & OFF & ON & ON & $+\mathrm{Vdc}$ & 0 & $-\mathrm{Vdc}$ \\
\hline V2 & 110 & ON & ON & OFF & OFF & OFF & ON & 0 & $+\mathrm{Vdc}$ & $-\mathrm{Vdc}$ \\
\hline V3 & 01 & OFF & ON & OFF & ON & OFF & ON & $-\mathrm{Vdc}$ & $+\mathrm{Vdc}$ & 0 \\
\hline V4 & 011 & OFF & ON & ON & ON & OFF & OFF & $-\mathrm{Vdc}$ & 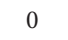 & $+\mathrm{Vdc}$ \\
\hline V5 & 001 & OFF & OFF & ON & ON & ON & OFF & 0 & $-\mathrm{Vdc}$ & $+\mathrm{Vdc}$ \\
\hline V6 & 101 & ON & OFF & ON & OFF & ON & OFF & $+\mathrm{Vdc}$ & $-\mathrm{Vdc}$ & 0 \\
\hline V7 & 111 & ON & ON & ON & OFF & OFF & OFF & 0 & 0 & 0 \\
\hline
\end{tabular}

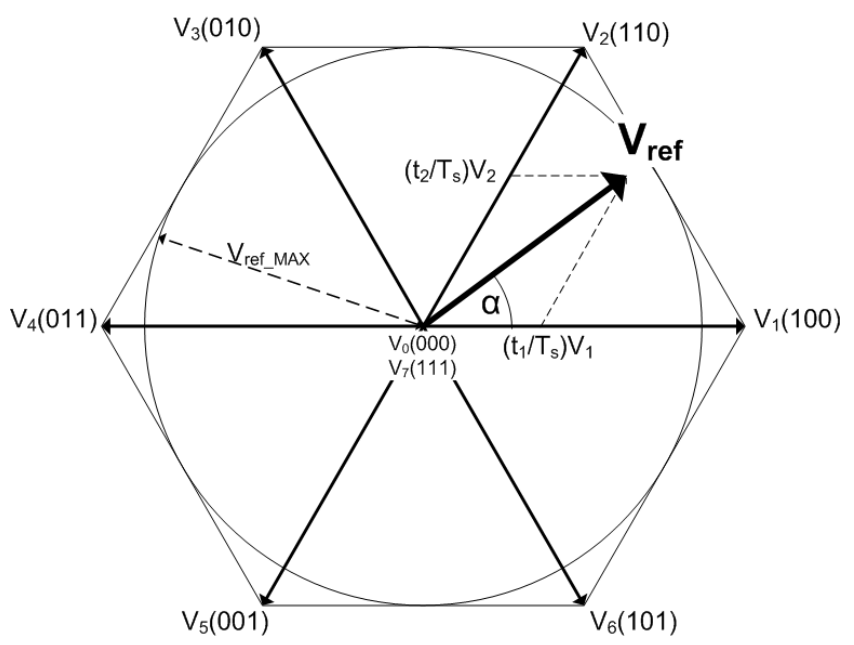

Figure 3. Switching pattern of SVPWM.

V2. Vref-MAX is the maximum amplitude of Vref within the modulation limit, beyond which may cause non-linear over-modulation.

The switching state vector $\mathrm{V} 1$ is applied for an interval $\mathrm{t} 1, \mathrm{~V} 2$ for $\mathrm{t} 2$ and the two zero vectors $\mathrm{V} 0$ and
V7 for interval t0, $\mathrm{t} 7$ respectively. So the total sampling interval:

$$
\mathrm{TS}=\mathrm{t} 1+\mathrm{t} 2+\mathrm{t} 0+\mathrm{t} 7
$$

In this same manner the total sample interval for remaining active vectors can be found. Resolving Vref and $\mathrm{V} 1, \mathrm{~V} 2$ along the $\alpha-\beta$ axis and by equating voltage-time integrals we get:

$$
\begin{gathered}
|\mathrm{Vref}| \mathrm{ts} \cos \gamma=|\mathrm{V} 1| \mathrm{t} 1+|\mathrm{V} 2| \mathrm{t} 2 \cos \frac{\pi}{3} \\
|\mathrm{Vref}| \mathrm{t} \sin \gamma=|\mathrm{V} 2| \mathrm{t} 2 \sin \frac{\pi}{3}
\end{gathered}
$$

Dividing both sides of equation above by $\mathrm{Vdc}$ and substituting abs $\left(\frac{V_{r e f}}{V_{d c}}\right)=\mathrm{a}$, we get

$$
\begin{gathered}
\mathrm{t}_{\mathrm{s}} \sin \gamma=\frac{\sqrt{3}}{2} \mathrm{t} 2 \\
\text { Or } \mathrm{t} 2=2 a t_{s} \sin \gamma / \sqrt{3} \\
\text { and } \mathrm{ts} \cos \gamma=\mathrm{t} 1+\frac{1}{2} \mathrm{t} 2
\end{gathered}
$$

Substituting the value of $\mathrm{t} 2$ from equation 12 in 13 and multiplying both sides of resulting equation by, we obtain $\frac{\sqrt{3}}{2}$

$$
\begin{aligned}
& \mathrm{t} 1=\frac{2 a t_{s}}{\sqrt{3}} \sin \left(\frac{\pi}{3}-\gamma\right) \\
& \mathrm{t} 0=\mathrm{t} 7=\mathrm{ts}-(\mathrm{t} 1+\mathrm{t} 2)
\end{aligned}
$$

Where a $=$ modulation index $=\operatorname{abs}\left(\frac{V_{r e f}}{V_{d c}}\right)$

The vector in the first sector can be determined by the switching patterns of time interval i.e $t 0, t 1, t 2$ and t7 respectively. The four time intervals change simultaneously when Vref goes from one sector to another for a particular modulation index say a. The full cycle is completed by six similar sectors with label 1,2 and so on up to 6. As Vref move over to sector 2, the inverter remains in switching state vector $\mathrm{V} 2$ for time interval $\mathrm{t} 1$ and in $\mathrm{V} 3$ for time $\mathrm{t} 2$. For sector $3, \mathrm{~V} 3$ for $\mathrm{t} 1$ and $\mathrm{V} 4$ for $\mathrm{t} 2$ and so on.

The block diagram of SVPWM as in Figure 4, constitutes three-phase diode rectifier, braking chopper, 
three phase inverter, induction motor, speed control and SVM block. The speed controller block is used to control the motor slip. In order to generate the required inverter voltage and frequency, the error in rotor speed this is computed by comparing the actual motor speed and the reference speed. The latter frequency is also used to generate the demanded inverter voltage in order to maintain the motor V/F ratio constant.

A simple simulation has been carried out in VSI Induction motor drive implementing the Space Vector PWM with the three phase source as in Figure 5.

The significant data obtained from the simulation results are as shown in Figure 6. The simulation using various Simulink/Sim power system blocks can be viewed in the following Figure 8.

The various blocks used for simulation can be explained as follows: A 3 phase, $460 \mathrm{~V}, 50 \mathrm{~Hz}$ voltage source has been used and its output voltage is rectified and boosted further and given to the three phase voltage source inverter and finally connected to the stator side of the DFIG. The gate pulse to the inverter is given after measuring the speed

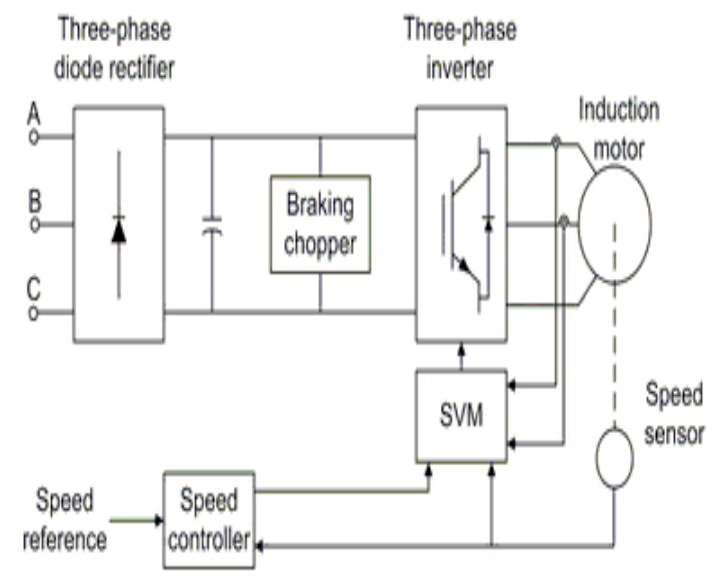

Figure 4. Block diagram of SVPWM.

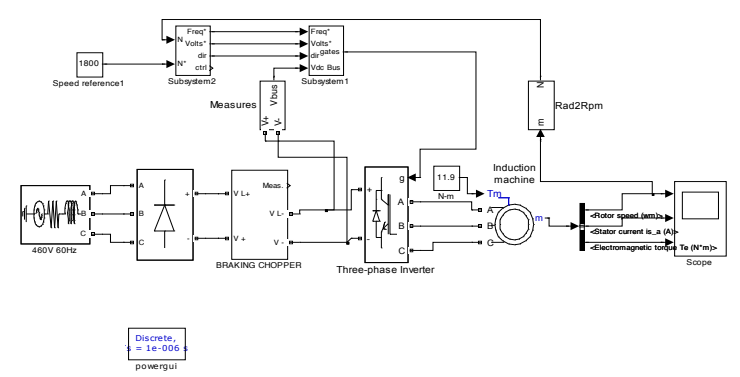

Figure 5. Space vector PWM VSI induction motor drive. of the magnetic flux of stator and torque using speed control and direct torque control blocks. Three phase output voltage from the measurement block is applied to the asynchronous machine of $7.5 \mathrm{~kW}, 400 \mathrm{~V}, 50 \mathrm{~Hz}, 1440 \mathrm{rpm}$. The rotor speed is compared with the reference speed in the speed controller block. The magnitude of the voltage and frequency measured from the speed of the rotor is given to SVPWM block. The SVPWM block will generate the required inverter voltage and frequency. The gate pulses for the inverter is determined by the on and off periods of the switching pattern. The inverter output is further fed to the grid converter and then to the load. The significant data obtained from the simulation results are as shown in Figure 8.
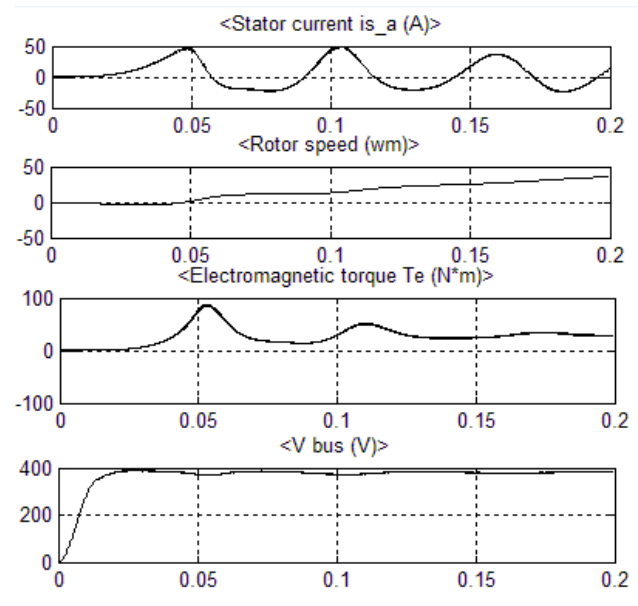

Figure 6. Response of stator current, wm, electromagnetic torque and bus voltage.

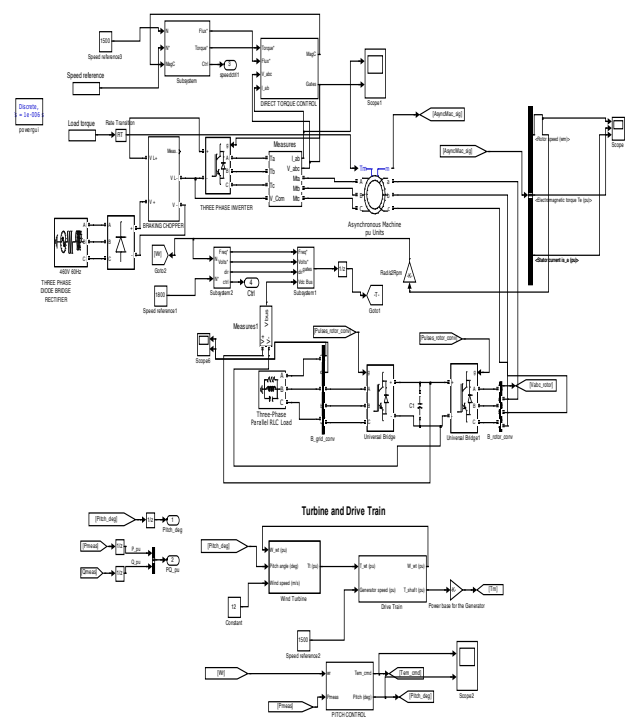

Figure 7. Simulation of DFIG with space vector PWM. 


\subsection{FFT Analysis for SVPWM}

The FFT analysis has been done using power gui in Simulink tool. The various quantities like rotor speed, electromagnetic torque and stator current have been taken for analysis.
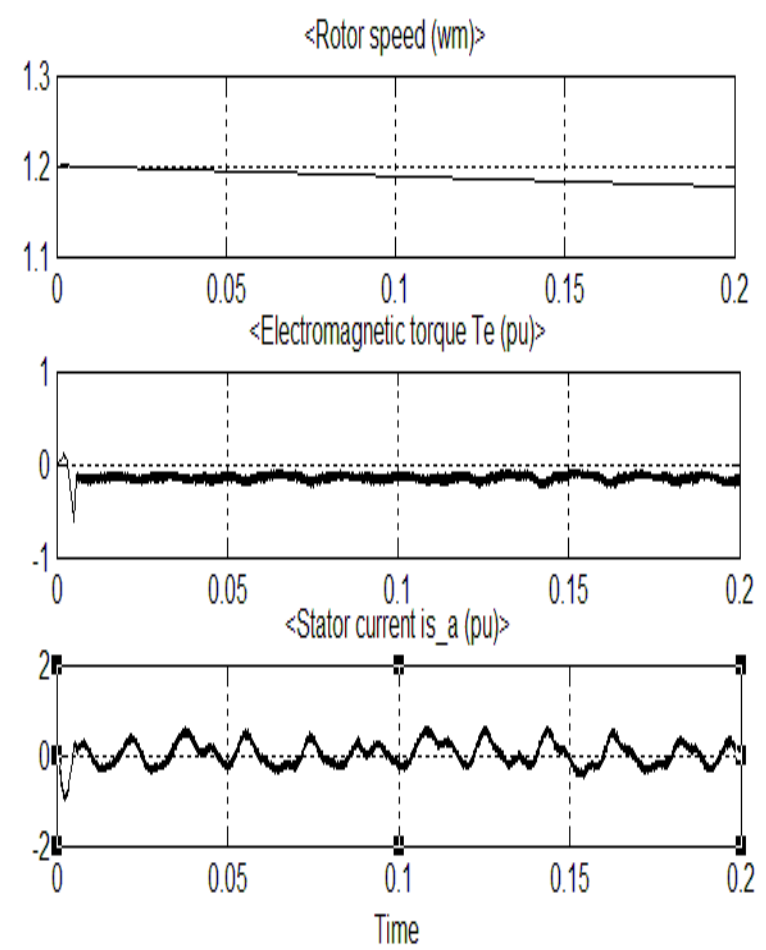

Figure 8. Simulated results.

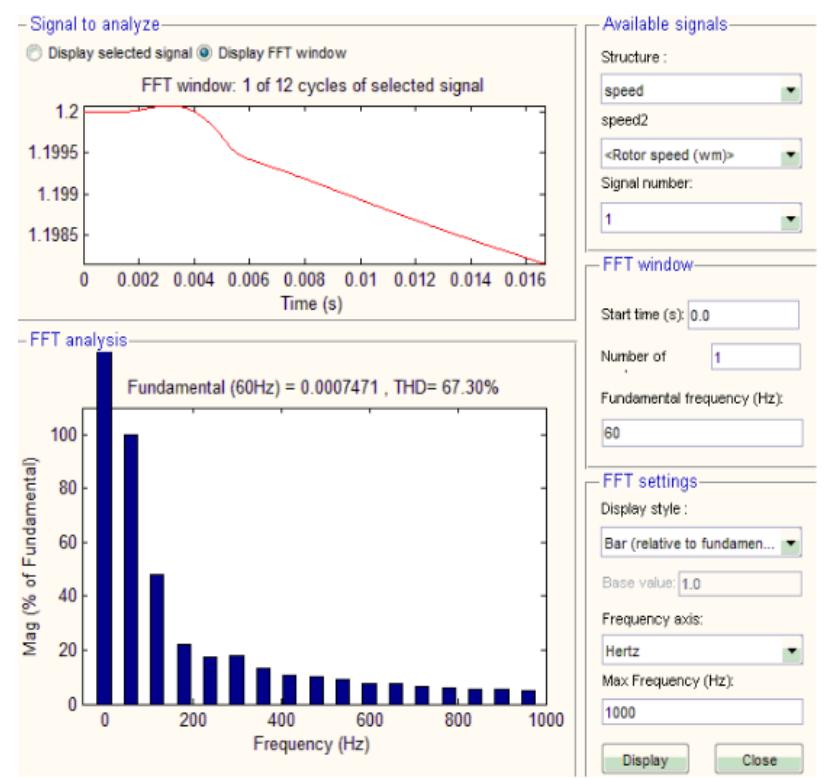

Figure 9. FFT analysis for rotor speed.

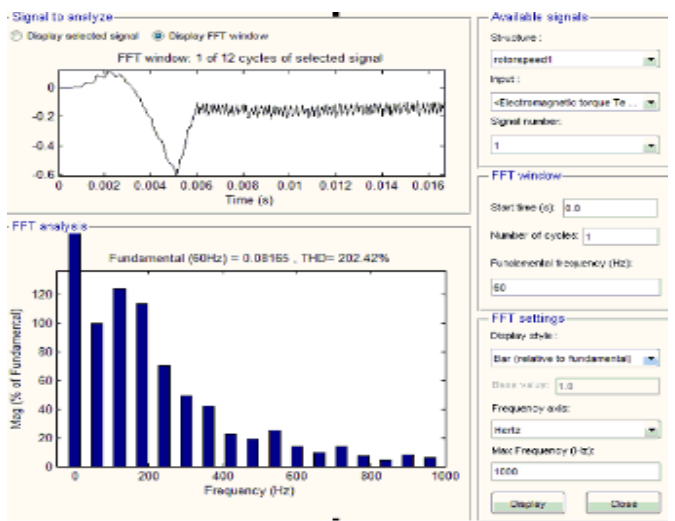

Figure 10. FFT analysis for electromagnetic torque.

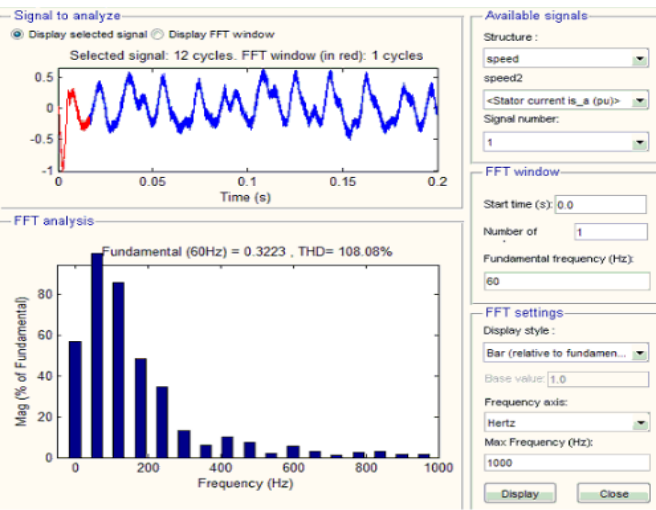

Figure 11. FFT analysis for stator current Ia.

Table 2. Simulated results

\begin{tabular}{|c|c|c|c|c|c|}
\hline \multirow[t]{2}{*}{ S.No } & \multirow[t]{2}{*}{$\begin{array}{c}\text { Simulation results } \\
\text { for DFIG }\end{array}$} & \multirow[t]{2}{*}{ SPWM } & \multirow[t]{2}{*}{ SVPWM } & \multicolumn{2}{|c|}{$\begin{array}{c}\text { Total Harmonic } \\
\text { distortion,THD in \% }\end{array}$} \\
\hline & & & & SPWM & SVPWM \\
\hline 1 & Rotor speed $\omega_{m}$ & 1.2 & 1.172 & 63.81 & 67.30 \\
\hline 2 & $\begin{array}{l}\text { Stator current ia } \\
\text { in p.u }\end{array}$ & 0.5 & 1 & 55.54 & 202.42 \\
\hline 3 & $\begin{array}{l}\text { Electromagnetic } \\
\text { torque,Te in p.u }\end{array}$ & -1 & -0.5 & 240.94 & 108.08 \\
\hline
\end{tabular}

\section{Conclusions}

SVPWM is widely used in variable speed drive applications. The simulation results are compared and analyzed by plotting the output harmonic spectra of rotor speed, stator current and electromagnetic torque and computing their Total Harmonic Distortion (THD) which is given in Table 2. Also this method of PWM 
generation gives better utilization of $\mathrm{dc}$ bus voltage for inverter and digital realization. In this algorithm total harmonic distortion are reduced due to rapid switching inherent. The THD is more or less equal for rotor speed while for electromagnetic torque it drastically reduced in SVPWM.

Future work can be done by using DSP control, intelligent control technique like FIS, ANFIS, GA Artificial neural network.

\section{References}

1. Jain S, Agarwal V. An integrated hybrid power supply for distributed generation applications fed by non-conventional energy sources. IEEE Trans Energy Conversion. 2008 Jun; 23(2):622-31

2. Ekanayake JB, Holdsworth L, Wu XG, Jenkins N. Dynamic modeling of doubly fed induction wind turbines. IEEE Trans Power Systems. 2003 May; 18(2):803-9.

3. Bai BJ, Rajesh Kumar Ch. Dynamic model and control of DFIG wind energy systems based on power transfer matrix using SVPWM. International Journal of Electrical and Electronics Engineering (IJEEE). 2014 Jan; 3(1):27-36.

4. Fadaeinedjad R, Moallem M, Moschopoulos G. Simulation of a wind turbine with doubly fed induction generator by FAST and Simulink. IEEE Trans Energy Conversion. 2008 Jun; 23(2):690-700.

5. Pokharel B. Modeling, control and analysis of a doubly fed Induction generator based wind turbine system with voltage regulation. [A Thesis Report]. Tennessee Technological University; 2011 Dec. 338.

6. Smajo J, Vukadinovic D. Electromagnetic torque analysis of a DFIG for wind turbines. WSEAS Transactions on Systems. 2008 May; 5(7):479-88. ISSN: 1109-2777.

7. Mounika K, Kiran Babu B. Sinusoidal and space vector pulse width modulation for inverter. International Journal of Engineering Trends and Technology (IJETT). 2013 Apr; 4(4):1012-7.

8. Raju NI, Islam MS, Uddin AA. Sinusoidal PWM signal generation technique for three phases voltage source inverter with analog circuit \& simulation of pwm inverter for load \& micro-grid system. International Journal of Renewable Energy Research. 2013; 3(3):647-58.

9. Sutikno T, Facta M. An efficient strategy to generate high resolution three-phase pulse width modulation signal based on field programmable gate array. International Journal of Computer and Electrical Engineering. 2010 Jun; 2(3):413-6.

10. Beltran B, Ahmed-Ali T, Benbouzid MEH. Sliding mode power control of variable-speed wind energy conversion systems. IEEE Trans Energy Conversion. 2008 Jun; 23(2):551-8.
11. Beig AR, Narayanan G, Ranganathan VT. Modified SVPWM algorithm for three level VSI with synchronized and symmetrical waveforms. IEEE Trans on Industrial Electronics. 2007 Feb; 54(1):486-94.

12. Hernandez A, Tapia R, Member, IAENG, Aguilar O, Garcia A. Comparison of SVPWM and SPWM Techniques for back to back converters in PSCAD. Proceedings of the WCECS; San Francisco: USA. 2013 Oct. p. 1-5.

13. Kumar KV, Michael PA, John JP, Suresh Kumar S, Simulation and comparison of SPWM and SVPWM control for three phase Inverters. ARPN Journal of Engineering and Applied Sciences. 2010 Jul; 5(7):61-74.

14. Kubeitari M, Alhusayn A, Alnahar M. Space vector PWM simulation for three phase DC/AC inverter. World Academy of Science, Engineering and Technology. 2012 Dec; 6(12):644-9.

15. Sasi D, Jisha Kuruvilla P. Modeling and simulation of SVPWM inverter fed permanent magnet brushless dc motor drive. International Journal of Advanced Research in Electrical, Electronics and Instrumentation Engineering. 2013 May; 2(5):1947-55.

16. Sivakumar P, Arutchelvi M, Soundarapandian R. Improved control strategy for grid connected scheme based on PV array and wind-driven induction generators. Indian Journal of Science and Technology. 2014 Nov; 7(S7):165-73.

17. Maaref M, Monsef H, Karimi M. A reliability model for a doubly fed induction generator based wind turbine unit considering auxiliary components. Indian Journal of Science and Technology. 2013 Sep; 6(9):5281-8.

18. Boroujeni HF, Eghtedari M, Memaripour A, Behzadipour E. Controller parameters design of doubly feed induction generator using Particle Swarm Optimization. Indian Journal of Science and Technology. 2011 Dec; 4(12):1635-8.

19. Abraham A, Padma Subramanian D. Impact of parameter variations on the steady state behavior of grid connected renewable energy conversion systems. Indian Journal of Science and Technology. 2014 Oct; 7(S6):48-55.

20. Rajaji L, Kumar C. Neural network controller based induction generator for wind turbine applications. Indian Journal of Science and Technology. 2009 Feb; 2(2):70-4.

21. Sedaghati R. A novel control strategy study for DFIG-based wind turbine. Indian Journal of Science and Technology. 2012 Dec; 5(12):3741-5.

22. Nasiri M, Milimonfared J, Fathi SH. Robust control of PMSG-based wind turbine under grid fault conditions. Indian Journal of Science and Technology. 2015 Jul; 8(13):52201.

23. Parvathy VM, Gnanambigai M. Stability analysis of the variable speed wind turbine using sliding mode control. Indian Journal of Science and Technology. 2015 Apr; 8(S7):467-70. 